\title{
A Cloud Computing Based for Clinical Information System
}

\author{
$1^{\text {st }}$ Syopiansyah Jaya Putra ${ }^{1}, 2^{\text {nd }}$ Muhamad Nur Gunawan ${ }^{1}, 3^{\text {rd }}$ Yanuar Wiby $^{1}, 4^{\text {th }}$ Dwi \\ Puspita Sari ${ }^{2}, 5^{\text {th }}$ Suci Ratnawati ${ }^{1}, 6^{\text {th }}$ Yuni Sugiarti ${ }^{1}$ \\ \{syopian@uinjkt.ac.id ${ }^{1}$, nur.gunawan@uinjkt.ac.id ${ }^{1}$, yannuar.wiby@gmail.com¹, dsardiyo@bu.edu², \\ suci.ratnawati@uinjkt.ac.id'1,yuni.sugiarti@uinjkt.ac.id $\left.{ }^{1}\right\}$ \\ UIN Syarif Hidayatullah Jakarta, Indonesia ${ }^{1}$ \\ Boston University USA ${ }^{2}$
}

\begin{abstract}
This In general, a health care clinic provides effective, safe, quality, ability to always prioritize the best interest of patients. Currently there are many health care clinics use papers for patient's medical records for information exchange that may cause vulnerability data misused. This case is caused by a cost limitation of particular clinic, time and human resources in providing information technology resources for several clinics connection. Cloud computing technology offers a great potential for a quick access for clinical information systems and solves problem in providing information technology resources. This paper focuses on the design of integrated clinical information systems along with the adoption of cloud computing services. The combination between information system development and cloud computing adoption methods is applied with four different steps including planning, analysis, design, and implementation. The result of this study is a clinical information system, such as patient administration systems, patient diagnosis services, pharmacy systems, laboratory service systems and medical record management systems that are integrated in each brand along with the adoption of cloud computing technology. The significant impact of the system implementation is reducing the clinic's operational costs, improving performance, easy and flexible use of the system as needed.
\end{abstract}

Keywords: Information Systems, System Development, Clinic, Cloud Computing

\section{Introduction}

Cloud computing is a form of internet service that can be accessed anywhere on demand that provides users comfort and quickly run with minimal management of service providers [1] [2].

Roadmap for Cloud Computing Adoption Model (ROCCA) for analyzing and determining the stages of the application process that can be applied to several cloud computing domains, as well as organizations, platforms and any cloud computing infrastructure. Thus, it can open the opportunity to utilize the model framework in various forms of organization including health services in clinics [3].

Cloud computing in the health sector offers great potential for quick access to clinical information. It maintains the confidentiality and integrity of information stored in all forms and provides data backup and recovery processes in extreme 
Cases that is very important in this field. A quick access to patient's medical history in any location can speed up the diagnosis process and quality of treatment, avoid complications, improve quality and save human lives [4].

A clinic is one of the health service providers that covers diagnosis, pharmacy, laboratory services, and patients' medical records [5]. The increasing demand for health services impacts on improving clinics services. There are many clinics with limited cost, time, and human resources in providing information technology resources to connect with all existing clinics, thus the utilization of cloud computing is an important requirement in providing the availability of information technology resources.

Past research has carried out clinical management information systems with medical records including drug management system, medical records, examinations, and services fees [6], while developed applications that can be printed on web-based patient medical records so it can backups data when the computer experiences any damages [7].

Research and development of cloud computing and interoperability in health information systems [4] and rubbish bank application development using cloud computing services [8]. Whereas the adoption of cloud computing for Small Medium Enterprise (SME) [9] and the implementation of private cloud for education institutions [10] [11].

Based on previous research, the development of information system uses rapid application development method [12] [13], however there are only few research on clinical medical record information that utilizes cloud computing. In this study, researchers conducted a research and development of clinical information system based on cloud computing with a combination of Rapid Application Development (RAD) method [14] and roadmap for cloud computing adoption (ROCCA) [3]. ROCCA is used as a cloud computing adoption roadmap and developed into a framework called the RAF (ROCCA Achievement Framework) [3]. The programming language used during the system development are PHP, JavaScript, HTML and Cascading Style Sheet (CSS), and MySQL used as database management system.

The purpose of this study is to design a clinical information system along with the adoption of cloud computing services that can creates a better management system with high speed for medical processes and improves a clinic service quality. At the end of this study, an information system clinic is produced that consists of patient administration system, nurse services, diagnosis of doctors or midwives, laboratory services, and clinical pharmacies that are integrated in each branch along with the adoption of cloud computing technology. This, it is expected that the clinical management will be better with a high speed for the information integration to improve the quality of clinical services.

\section{Methods}

RAD is used during the development of this system, it has four different phases starting from planning, analysis, design, and implementation. However, during the design to implementation phase, there is a combination with ROCCA as a roadmap to guide in adopting cloud computing technology. The cloud computing service on the clinic's information system applies the platform as a service (PaaS) service model with a private cloud deployment model.

The ROCCA adoption model has been chosen based on system design requirements and implementation into cloud computing. It is shown in the Figure 1 below. 


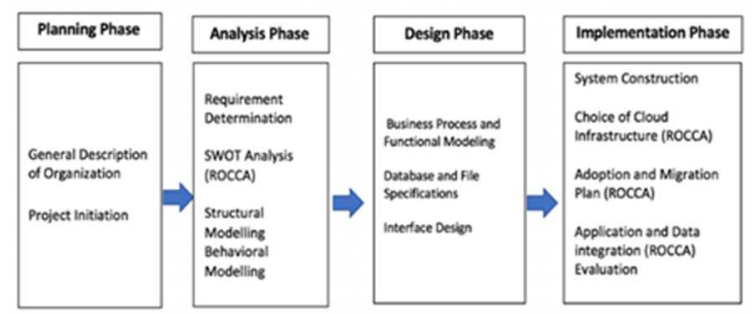

Figure 1. Study Framework

There were four phases that are described in the sections below.

\subsection{Planning Phase}

A general description of organization is a basic process stage for understanding an overall view of organization, including profile, both vision and mission, structure, and project initiation. A project initiation in the organization summarizes a desire information system needed by a clinic.

\subsection{Analysis Phase}

An analysis phase is a stage when the study questions were answered. For example, the stakeholders involve in the system, people who will use the system, time and location where the system will be implemented. In this phase also researchers understand user's needs, work culture, readiness of organization to adopt cloud computing technology. It also produces a determination requirement that provides an overview of the requirements of the system design process, furthermore strengths weaknesses opportunities and threats (SWOT) analysis [3] [5] used to analyze the strength, weakness, opportunity and obstacle of the implementation organization of cloud computing-based clinic information system.

\subsection{Design Phase}

The result of the previous phase produces a proposed system requirements and specifications. Those information is described using the Unified Modelling Language (UML) use case diagram for business process and functional modeling. The design phase also generates a database schema as a database design and file specification and produces an interface picture of system.

\subsection{Implementation Phase}

This phase produces system construction, choice of cloud infrastructure, and adoption and migration plan. In the system construction stage, black-box testing technique is used to test the code during the development process. The choice of cloud infrastructure is used during this phase along with the adoption and migration plan planning.

In the application and data integration phase, it prepares the process of migrating to cloud computing by integrating and adapting applications and data that will be migrated with the target cloud platform and infrastructure.

The final step in this phase is the system user evaluation that involves user application testing and completion of satisfaction evaluation by users [16] [17][18]. The evaluation is in a form of questionnaire deployed by researchers where the responses is analyzed using a percentage calculation to retrieve evaluation results. 


\section{Results and Discussion}

The results of the application integration of the ROCCA and RAD methods resulted in the design and implementation of a cloud based clinical information system in the form of patient administration systems, patient diagnosis services, pharmacy systems, laboratory service systems, and medical record management systems.

There were four results that are described in the sections below.

\subsection{Planning Phase}

This phase identifies business reasons and expected value from Clinics in developing a system. In general, system requirement includes five elements, including project sponsor, business needs, business requirements, business value, and specific requirements.

\subsection{Analysis Phase}

Analysis phase consists of three main activities, namely requirement determination, SWOT and business process analysis, and functional modelling. Those activities are described in the following sections.

\subsubsection{Requirement Determination}

Requirement determination consists of functional requirements and non-functional requirements. The functional requirements include:

The system can manage, store, and integrate all patients' history data properly.There are three functions in the managing the systems, namely add, edit, and print out. The system can manage patient queues based on health service requests.Clinical service data and all information about clinic can be arranged easily the system administrator.The system provides notification that facilitates doctors, midwives, and clinics for patient queue information.

The system provides user authentication when logged in and distribution of authority. The non-functional requirements include:The system can streamline the time in the clinical health service process. The system display is a user friendly, so it is easily learned and used.The system can reduce human errors. The system presents actual and accurate data and information. The system can reduce the occurrence of misuse of medical record data.

\subsubsection{SWOT Analysis}

Keep your text and graphic files separate until after the text has been formatted and styled. Do not use hard tabs, and limit use of hard returns to only one return at the end of a paragraph. Do not add any kind of pagination anywhere in the paper. Do not number text heads-the template will do that for you.

Table 1. SWOT Analysis Metrics

\begin{tabular}{|c|c|}
\hline Strengths & Weaknesses \\
\hline
\end{tabular}




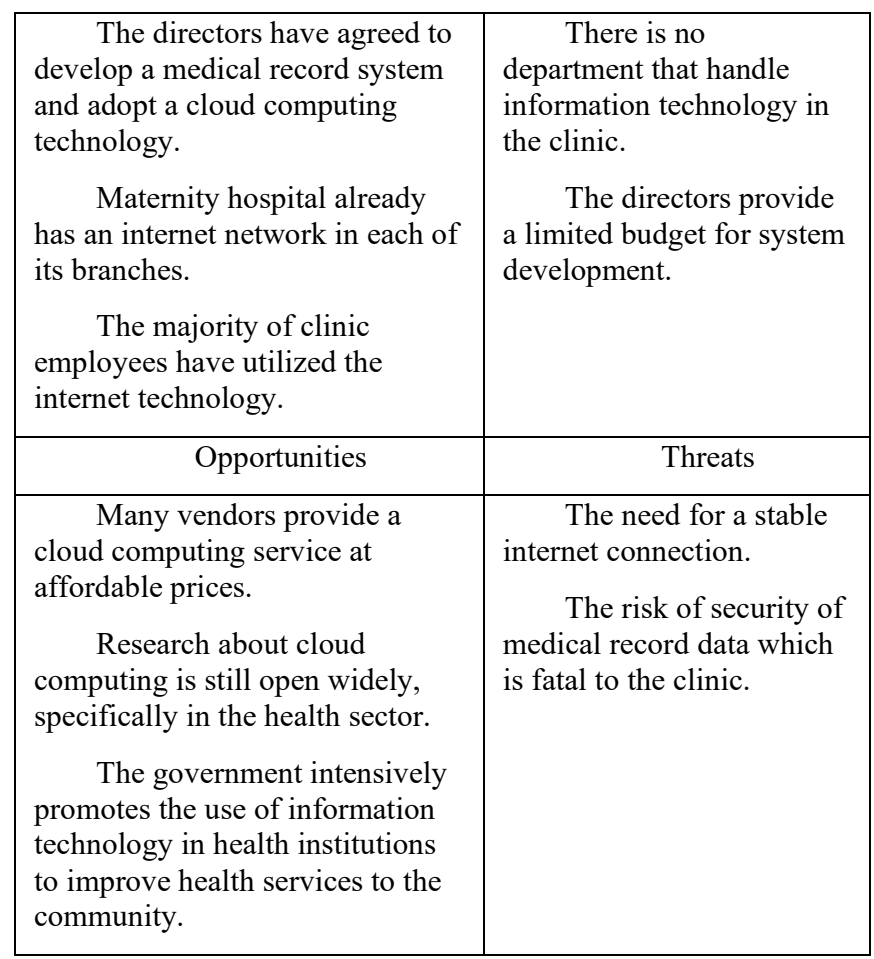

The description of analysis of SWOT metrics is described in the following section.

a. Strength and Opportunity Strategy

The strategy uses parts of strength and opportunity to maintain, build, and increase the potential the exists.

The board of directors has agreed to develop a medical record system and adopt cloud computing technology in line with the government which is aggressively promoting the use of information technology in health institutions to improve health services to the community.

Computer facilities that use the internet technology supported by cloud computing service provider vendors that are increasingly developing.

Researchers will more easily implement their research in the clinic because it is supported by employee knowledge about the use of internet technology.

b. Strength and Threat Strategy

This strategy will use a part of excellence and threat aiming to use the power that is owned to reduce the impact of threats that may occur.

The commitment of clinic managers to meet the needs of internet services in clinic is highly needed due to the necessary needs of stable internet services.

Employee knowledge about the internet usage a utilization of medical record data is very important to anticipate the risk of security for medical record data. 


\section{c. Weakness and Opportunity Strategy}

This strategy uses weaknesses and opportunity to diminish and minimize the weaknesses using the opportunities. The existence of cloud computing services vendor that offers many solution of the general problems, such as a minimum number of employee to manage information technology, reduction in operational costs, and inadequate infrastructure.

\section{d. Weakness and Threat Strategy}

This strategy uses weakness and threat to counteract the worst that will arise from the impending threat.

A stable internet needs can be overcome by the commitment of clinic managers to collaborate with s good service provider vendors.

Establish a particular department to handle information technology issues used to maintain and monitoring systems.

Provide training to employees for the use of the system and utilization of medical record data

\subsection{Design Phase}

This phase consists of business process and functional modelling, database schema, and user interface design. The details for each activity is described in the following section.

1. Business Process and Functional Modeling

Business clinic process information system consists of objects, receptionists, nurses, midwives, doctors, cashiers, pharmacies, directors, and administrators. The user can do nine activities: (1) login process to enter the system, (2) service registration process to print out patient number, (3) the process of printing the patients queue number based on the selected service, (4) laboratory service process, (5) midwife process or doctor preview the queue list based on patient registration number, (6) the process of inputting the diagnosis data and medicine prescription, (7) the pharmacy previews the list of queue after midwives or doctors observation and then pharmacy confirms the medicine for patient, (8) pharmacy drug management, (9) bill overviewed by cashier and payment confirmation.

The business process information system clinic consists of a patient administration system, a patient diagnostic system, a pharmacy system, a laboratory service system, and a medical record management system.

\section{A Patient Administration System}

This system is operated by two actors (Figure 2): receptionist and cashier. A Receptionist has an authorization to register both a former patient and a new patient, then print out the medical record number so that a cashier able to confirm the service fee and payment.
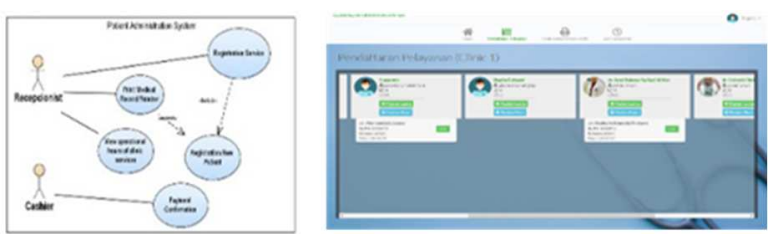

Figure 2. A Patient Administration System

3. A Patient Diagnosis System 
This system is operated by three actors (Figure.3): a nurse, a midwife, and a doctor. Those actors are able to login to the system to view patient queue, entry a result of diagnosis, and print out a patient health certificate.
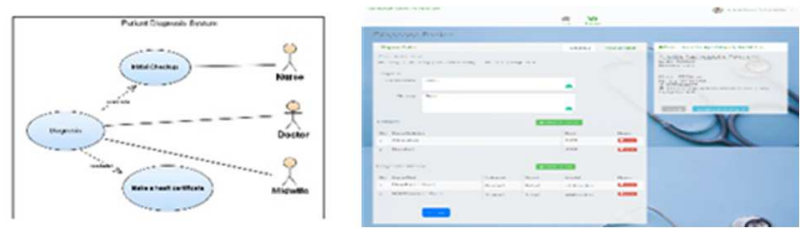

Figure 3. A Patient Diagnosis System

4. A Pharmacy System

This system is operated by three actors (Figure.3): a nurse, a midwife, and a doctor. Those actors are able to login to the system to view patient queue, entry a result of diagnosis, and print out a patient health certificate.
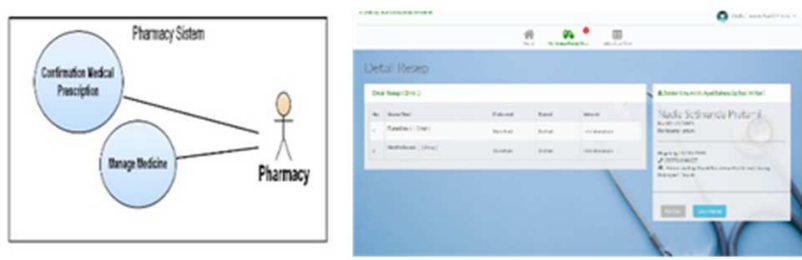

Figure 4. A Pharmacy System

5. A Laboratory Service System

In Figure 5. A laboratorian is the only actor for this system who can view patient queue, laboratory test result, entry laboratory result, print out the laboratory result, and manage any services of laboratory test.

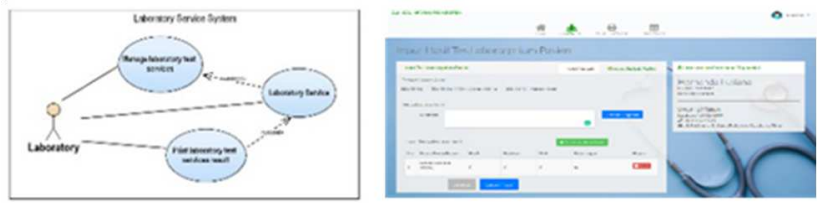

Figure 5. A Laboratory Service System

6. A Medical Record Management System

In the medical record management system there are two actors namely directors and administrators as in Figure 6. Administrators are super users who have a full access to view patient data, view medical record data, manage users, manage clinical service schedules, manage drug data, manage laboratory test service data, organize clinic profiles and see clinical services. In addition, administrator can also manage data types of actions to patients for the purposes of diagnostic data by doctors. And the director has access to view patient data, view medical record data, print medical record reports, and view clinical services.
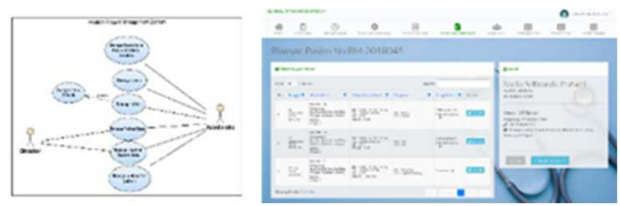
Figure 6. A Medical Record Management System

7. Database Schema

The researchers develop database to store data that supports the system so that it can run properly. The database schema developed consists of 16 tables. There are clinical_profile, branch_clinic, patient, medical_record, registration_service, bill_finance, operational_hour, type_clinical service, prescription_medicine, drug_receipt, $\overline{d r u g, ~ d i a g n o s i s, ~} \overline{c h e c k}$, lab_test_result, lab_test_detail, lab_type_service.

\subsection{Implementation Phase}

There are five activities in the implementation phase, including system construction, choice of cloud computing infrastructure, adoption and migration plan, application and data integration, and system evaluation.

a. System Construction

The proposed system is a web-based application. The system was built using the PHP programming language using the Codeigniter framework, MySQL as a database management system, XAMPP as a web server, bracket as a text editor, and Mozilla Firefox edition as a browser to run the system. The main purpose of the system, the researchers used the black-box method to conduct testing on the information system of the clinical medical record based on cloud computing at the maternity hospital.

b. Choice of Cloud Computing Infrastructure

Clinics must choose a cloud service model that suits their information system needs. There are three cloud computing service models that can be chosen, namely SaaS (Software as a Service), PaaS (Platform as a Service), and IaaS (Infrastructure as a Service). In addition, for the implementation model, you can choose Private Cloud or Public Cloud. Based on the results of the SWOT analysis there is support from the internal clinic for information technology information and along with clinical conditions, then SWOT strategy analysts produce infrastructure services that are easily implemented and can be considered data security services, then the chosen cloud infrastructure is PaaS services (Platform as a Service) with the private cloud deployment model. Because the PaaS service does not need to control the basic cloud infrastructure. Including network, server, operating system, or storage, but has control over the application deployed and possible configuration settings for the applicationhosting environment.

\section{c. Adoption and Migration Plan}

Based on the needs of cloud service providers such as those in the SWOT analysis, the deployment of the private cloud and service model (PaaS) Platform as a Service will be implemented. So, at this stage the writer will determine for the needs of the cloud computing service provider vendors accordingly. Strategy analysts produce strategies for the needs of cloud service provider vendors that are able to meet the varied and easy service requirements for their use. Cloud computing service providers make it possible to build and host web applications in suitable programming languages without managing infrastructure, so as to support the operating system used and enable rapid and precise dissemination of information and cost efficiency.

So, for cloud computing needs focused on the clinical information system that will be built. So, the specifications needed for cloud computing are at minimum core 1, ram $1.75 \mathrm{~GB}$, 10 GB storage according to the standard B1 package. But in this information system prototype uses a free and shared package. Because this package is intended for the development and 
testing of the system to be built. The cloud system scheme for clinical information systems can be seen in Figure 7. Cloud service providers use Microsoft Azure with PaaS (Platform as a Service) services for Web Apps. In the WEB Apps service, we install the cloud server and its database. Each branch of the clinic must be connected to the internet to be able to access WEB Apps services. The cloud distribution model uses private cloud namely infrastructure and applications are only used for internal clinics, this can reduce the risk of existing data security.

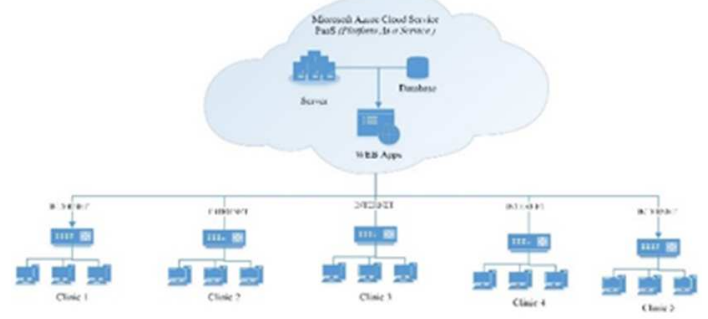

Figure 7. Cloud Computing Based for Clinic Information System Infrastructure

d. Application and Data Integration

In this stage, it prepares the process of migrating to cloud computing by integrating and adapting applications and databases that will be migrated with the target cloud platform and infrastructure. Based on the existing system development, explain the specifications needed for the system development stage. Then explaining the provider of cloud computing with the services used, namely PaaS (Platform as a Service) for WEB Apps, it is necessary to adjust it for data integration and application. There are several different configurations from local servers with XAMPP that use Apache WEB Server with Microsost's WEB Server. So for the development of applications with PHP language must be adjusted from Microsoft-IIS / 10 and the database using the MySQL server type. As is known, the IIS web server is made by Microsost and can only run on Windows, of course different for setting up the web server configuration. As in Apache, using .htaccess must be translated in IIS to become a Web.configh file. While for the PHP programming language and MySQL database there is not much that must be adjusted.

e. Application and Data Migration

The next step is the migration process for applications and data into the Microsoft Azure WEB Apps as determined and 


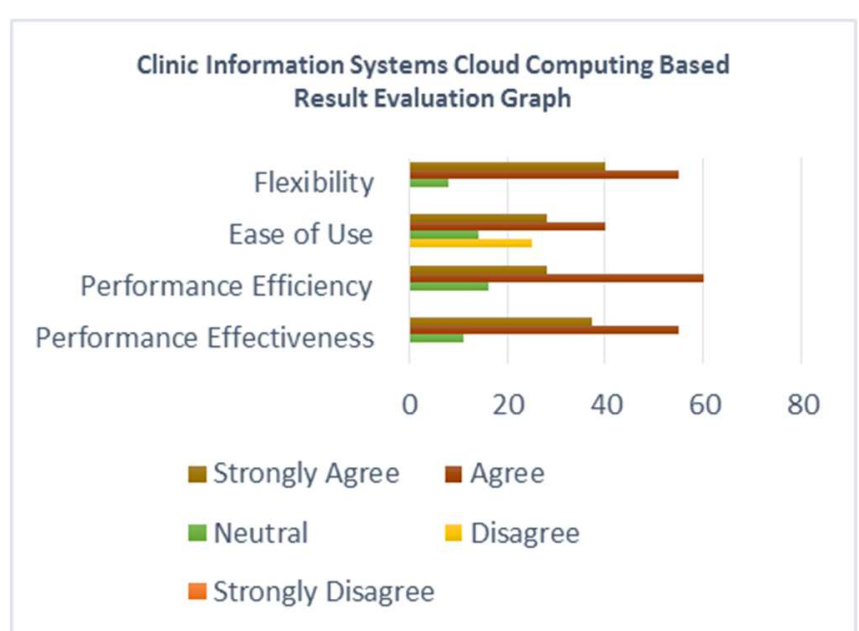

Figure 8. Clinic Information System Cloud Computing Based Result Evaluation Graph

integrated. Previously to deploy the system we must have an account from Microsoft Azure to be able to enter porta.azure.com. To get an account can be individual or on behalf of the organization.

After entering the azure portal, then create a new WEB Apps service by adding a service and then selecting WEB Apps and selecting WEB App and MySQL. Figure 7 above shows the process of determining the service configuration for the WEB App that will be used. Starting from determining domain names, types of server services, and services for databases. For this reason, the author uses an unpaid trial service to try to use the Microsoft Azure WEB App. After the process is successful in determining service configuration then you will get detailed service configuration for the application and database.

f. System Evaluation

The following is the recapitulation of the results of the evaluation. This questionnaire uses respondents according to the number of actors, namely 36 (thirty six) people according to the employee class.

Figure 8 above shows that based on the performance effectiveness aspect, the highest average value is $55 \%$ who agreed. On the efficiency aspect, the highest average score is $60 \%$. In the aspect of ease in using the highest average value, with a value of $40 \%$, it was agreed. Whereas in the aspect of system flexibility the highest average value is $55 \%$ of the respondents agree. Thus, it can be concluded that not many agree with the ease of use. This is realized in the application there are still shortcomings, namely there is no help information on using the application. But with this system the user agrees that the system effectively helps users and the system is also able to improve the efficiency of the user's work. In addition, the system can also be used flexibly. Support with the presence of many branches in the clinic.

\section{Conclusion}

This study is successfully developed a cloud computing information system based on a combination of the RAD method and the roadmap for ROCCA model. This clinic information 
system consists of a patient administration system, a patient diagnostic system, a pharmacy system, a laboratory service system, and a medical record management system.

This cloud-based clinic information system is able to reduce paper usage to overcome data loss, misuse of data, and make exchange and data searching between clinics easier. This system is also able to integrate information between clinics so that it can cut operational costs. Using a cloud computing technology, the implementation of the system becomes easier, flexible, and can be used as needed. It is expected that the future researchers will develop a system that is integrated with the finance, insurance, and inventory parts of the pharmacy section. Likewise, the implementation of security systems in networks and databases for this clinical information system.

\section{References}

[1] Jadeja, Y. and Modi, K. Cloud Computing-Concepts, Architecture and Challenges. International Conference on Computing, Electronics and Electrical Technologies. 2012

[2] P. Mell and T. Grance, "The NIST definition of cloud computing," National Institute of Standards and Technology. NIST Special Publication 500-292, Gaithersburg, United Ststes of America, 2011.

[3] F. Shimba, "Cloud computing: Strategies for cloud computing adoption," Dissertations, 2010.

[4] O.-S. Lupşe, M. M. Vida, and L. Stoicu-Tivadar, "Cloud computing and interoperability in healthcare information systems," in The First International Conference on Intelligent Systems and Applications, pp. 81-85.2012

[5] M. K. R. Indonesia,( Regulation of the Minister of Health of the Republic of Indonesia Number 55 of 2013 concerning the Implementation of Medical Recorder Works) "Peraturan Menteri Kesehatan Republik Indonesia Nomor 55 Tahun 2013 Tentang Penyelenggaraan Pekerjaan Perekam Medis." p. 18, 2013

[6] Y. W. Triaji, R. Kridalukmana, and E. D. Widianto, (Development of Clinical Management Information System with Medical Records: Case Study at Kebon Arum Boyolali Clinic) "Pembuatan Sistem Informasi Manajemen Klinik dengan Rekam Medis: Studi Kasus di Klinik Kebon Arum Boyolali," J. Teknol. dan Sist. Komput., vol. 5, no. 1, pp. 15-22, 2017

[7] J. Widya, Designing Web-Based Medical Record Information System Development (Case Study: Psycho-Neuro-Geriatric Nursing Home Saras Puri Saras' Semarang) "Rancang Bangun Sistem Informasi Rekam Medis Berbasis Web (Studi Kasus: Rumah Perawatan Psiko - Neuro - Geriatri 'Puri Saras' Semarang), ”J. Teknol. Inf. dan Komun. STMIK ProVisi Semarang, 2014.

[8] S. U. Masruroh, S. E. Suciasih, and H. B. Suseno, (Application development of waste banks uses cloud computing information technology services in clean jasmine waste banks ) "Pengembangan aplikasi bank sampah menggunakan layanan teknologi informasi cloud computing pada bank sampah melati bersih,” J. Tek. Inform., vol. 8, no. 2, 2015.

[9] A. Fardani and K. Surendro, (Strategy for Adopting Cloud Computing-Based Information Technology for Small and Medium Enterprises in Indonesia) "Strategi Adopsi Teknologi Informasi Berbasis Cloud Computing untuk Usaha Kecil dan Menengah di Indonesia," in Seminar Nasional Aplikasi Teknologi Informasi (SNATI), 2011.

[10] M. S., Suprayogi, \& P. T. Pungkasanti, (Subdomain Mapping On University Semarang Cloud Server Using Port Forwarding and Reverse Proxy Methods) "Pemetaan Subdomain Pada Cloud Server Universitas Semarang Menggunakan Metode Port Forwarding dan Reverse Proxy". Kinetik, 2(1), 63-70.2017

[11] A., Solichin, \& Z. A. Hasibuan, (Cloud computing based information technology architecture modeling for higher education institutions in Indonesia) Pemodelan arsitektur teknologi informasi berbasis cloud computing untuk institusi perguruan tinggi di Indonesia. Semantik, 2(1). 2012

[12] S.J. Putra. Development of Accounting Information System on state owned property: case study at Regional Office of Directorate General of Treasury, province of Lampung-Indonesia. 
Proceeding of the 11th International Conference on Information Integration and Web-based Applications and Services. ACM. 2009.

[13] D.P. Sari, S.J. Putra and E.Rustamaji, 2014. The Development of Project Monitoring Information System (Case Study: PT Tetapundi Prima Kelola). In Proceeding of the 3rd International Conference on Information Technology for Cyber and IT Service Management (CITSM 2014). Pp.39-43. Jakarta, Indonesia.2014

[14] A. Dennis, B. H. Wixom, and D. Tegarden, Systems analysis and design with UML Version 2.0: An object-oriented approach with UML. John Wiley \& Sons, 2012.

[15] Dyson, R. G.. Strategic development and SWOT analysis at the University of Warwick. European journal of operational research, 152(3), 631-640.2004

[16] Putra, S. J., Ahlan, A. R., \& Kartiwi, M. A Coherent Framework for Understanding the Success of an Information System Project. TELKOMNIKA (Telecommunication Computing Electronics and Control), 14(1), 302-308. 2016

[17] Putra, S. J., Rosalina, R., \& A'ang Subiyakto, M. N. G. Extending the End-user Computing Satisfaction with Security Measures. The 6th International Conference on Information Technology for Cyber and IT Service Management (CITSM 2018). IEEE.2018

[18] S.J. Putra, A. Subiyakto, I. Yunita, M.N. Gunawan,Y. Durachman. Assessing the User Satisfaction Perspectives of Information System: A Library Case Study in Indonesia. Indonesian Journal of Electrical Engineering and Computer Science. Vol.12,No.1, october 2018,pp.95-101. 